\title{
Synchronous cancers of gallbladder carcinoma and combined hepatocellular cholangiocarcinoma: an unusual case and literature review
}

\author{
Zhan-Guo Zhang ${ }^{1 \dagger}$, Yan Chen ${ }^{2 \dagger}$, Ran $\mathrm{Ji}^{3}$, Ya-Jie Zhao ${ }^{3}$, Jian Wang ${ }^{3}$, Lily Robinson ${ }^{4}$, Xiao-Ping Chen ${ }^{5}$ \\ and Lei Zhang ${ }^{1 *}$ (I)
}

\begin{abstract}
Background: Synchronous primary cancers in gallbladder and liver are rarely reported. Here we report an unusual case of synchronous cancers of gallbladder carcinoma and combined hepatocellular cholangiocarcinoma.

Case presentation: Several lesions in the gallbladder and in adjacent parenchyma of liver were discovered in a 65-years-old woman by imaging examination. Surgical resection was performed following a diagnosis of primary gallbladder carcinoma with local hepatic metastasis. Histological examination confirmed the diagnosis of primary gallbladder carcinoma, and the lesions in the liver consisted of hepatocellular carcinoma simultaneously with cholangiocarcinoma. Adjuvant chemoradiation therapy was not performed due to the patient's refusal of the treatment. Unfortunately, the patient died of widespread metastasis 8 months after the operation.
\end{abstract}

Conclusions: The disease needed to be differentially diagnosed from gallbladder carcinoma with hepatic metastasis. Aggressive surgical approach should be based on a balance between the risk of surgery (morbidity and mortality) and the outcome.

Keywords: Synchronous primary cancers, Gallbladder carcinoma, Combined hepatocellular cholangiocarcinoma, Diagnosis, Surgical treatment

\section{Background}

With the widespread of regular medical check-ups and the improvement in early diagnosis, the occurrence of synchronous primary cancers (SPC) is becoming more frequent in the past decade [1]. However, the knowledge of the clinical features and outcomes of SPC remains limited. A high incidence of SPC has been found in the liver or gallbladder; nevertheless, SPC involving both liver and gallbladder are regarded as a rare occurrence, and only seven cases have been reported in English literature for the past seventy years. Here, we reported a case of

\footnotetext{
* Correspondence: zhangl@tjh.tjmu.edu.cn

'Zhan-Guo Zhang and Yan Chen contributed equally to this work.

${ }^{1}$ Hepatic Surgery Center, Institute of Hepato-Pancreato-Bililary Surgery, Tongji

Hospital, Tongji Medical College, Huazhong University of Science and

Technology, Wuhan 430030, People's Republic of China

Full list of author information is available at the end of the article
}

synchronous double cancers of gallbladder carcinoma (GC) and combined hepatocellular cholangiocarcinoma $(\mathrm{CHC})$.

\section{Case presentation}

A 65-years-old female Chinese woman was admitted to our hospital with the chief complaint of abdominal pain in the right upper quadrant for the past 20 days. There was no remarkable family, medical or genetic history. The patient was in good general health and had no significant weight loss. Her vital signs (including heart rate, respiration rate, blood pressure and body temperature) were within normal limit. There were two positive signs during the physical examination, anemic conjunctiva and tenderness in the right upper quadrant. Complete blood count and serum biochemistry data on admission remained normal except hemoglobin, $9.5 \mathrm{~g} / \mathrm{dl}$. Significant abnormalities

(c) The Author(s). 2018 Open Access This article is distributed under the terms of the Creative Commons Attribution 4.0 International License (http://creativecommons.org/licenses/by/4.0/), which permits unrestricted use, distribution, and 
were found in the tumor marker, demonstrated by a normal serum level of alpha-fetoprotein (AFP; $4.85 \mathrm{ng} / \mathrm{ml}$, normal: $0-8.78 \mathrm{ng} / \mathrm{ml}$ ) and elevated levels of carcinoembryonic antigen (CEA; $16.3 \mathrm{ng} / \mathrm{ml}$, normal: $0.5-5.0 \mathrm{ng} /$ $\mathrm{ml}$ ), carbohydrate antigen 125 (CA125; $371.2 \mathrm{U} / \mathrm{ml}$, normal: 1-35 U/ml) and CA19-9 (358.96 U/ml, normal: 2$37 \mathrm{U} / \mathrm{ml}$ ). Multi-detector computed tomography (CT) scan of the abdomen showed distension of the gallbladder with gallbladder stones and several homogeneous high-density masses in the gallbladder fundus (intense enhancement on artery and portal venous phase, low attenuation on delayed phase), and multiple hypodensity tumorous lesions adjacent to the gallbladder (mild irregular enhancement at the periphery of the lesions on artery and portal venous phase, further enhancement on delayed phase), which were located in the lower part of segment IV of the liver (Fig.1a-d). Magnetic resonance imaging (MRI) with perfusion-weighted imaging confirmed the presence of gallbladder stones and solitary $3 \times 3 \mathrm{~cm}$ enhanced lesions in the gallbladder, and $6.2 \times 4.5 \mathrm{~cm}$ hypovascular tumors in the liver (Fig. 2a-f). The data of abdominal ultrasonography was consistent with the above data. Thus, the preoperative diagnosis was GC with hepatic metastasis.

The patient was informed of the risks involved with the surgery before consent for the operation was obtained. After sufficient preoperative preparation, the patient underwent an exploratory laparotomy. During laparotomy, the gallbladder was enlarged to $16 \times 6 \times$ $6 \mathrm{~cm}$ and showed wall thickening (the thickness was $1 \mathrm{~cm})$. There was a palpable mass felt on the surface of the gallbladder fundus portion. Exploration also showed an $8 \times 6 \mathrm{~cm}$ rigid lesion fused by multiple masses in liver segment $\mathrm{IVb}$ and $\mathrm{V}$ and $\mathrm{a} 1 \times 1 \mathrm{~cm}$ lesion in segment VIII. Moreover, sporadic lesions on the diaphragm and enlarged station 8 lymph nodes were seen. The patient underwent cholecystectomy, resection of liver segment $\mathrm{V}$, of the lower part of segment IV and partial segment VIII, regional lymphadenectomy and resection of lesions on diaphragm.

The post-operative histopathological examination revealed synchronous double cancers in the liver and gallbladder, which were GC (well-differentiated papillary adenocarcinoma invading the muscularis propria) and $\mathrm{CHC}$ (Fig. 3a and b). The examination also showed that the metastases in lymph nodes and diaphragm were both from $\mathrm{CHC}$ in the liver.

After 10 days of recovery, the patient was discharged without complications. Adjuvant chemoradiation therapy was not performed due to the patient's refusal. Unfortunately, the patient died of widespread metastasis 8 months after the operation.

\section{Discussion and conclusions}

The incidence of multiple primary cancers (MPC) has been reported to vary from 0.7 to $11.7 \%$ [2]. The diagnostic criteria have by adopted by most clinicians for MPC: 1) each tumor must be malignant determined by histological evaluation; 2) the tumors must be separate and distinct; 3 ) the probability that one is a metastasis from the other tumor must be ruled out [2, 3]. According to these criteria, this case was determined to be
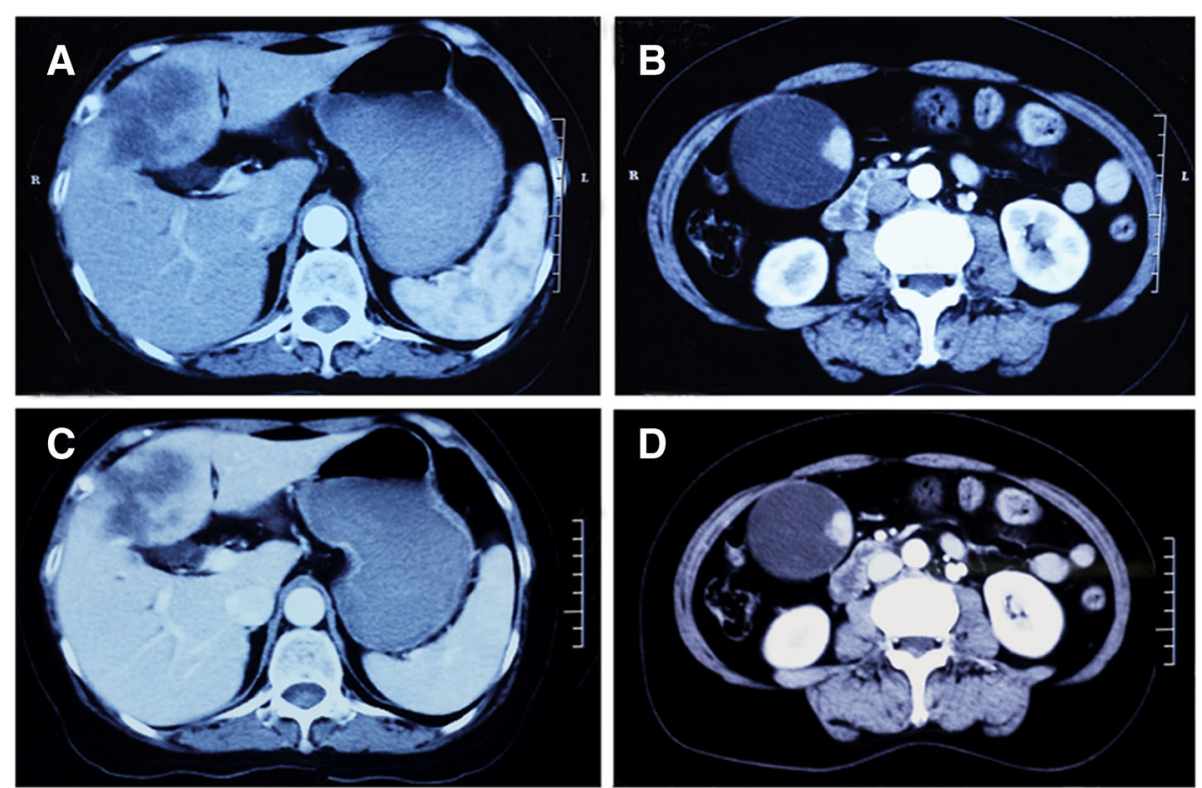

Fig. 1 Abdominal multi-detector computed tomography-scan showing $3 \times 3 \mathrm{~cm}$ mass in gallbladder and $6.2 \times 4.5 \mathrm{~cm}$ lesion in segment IVb of the liver. $\mathbf{a}$ and $\mathbf{b}$ Artery phase, $\mathbf{c}$ and $\mathbf{d}$ Venous phase 

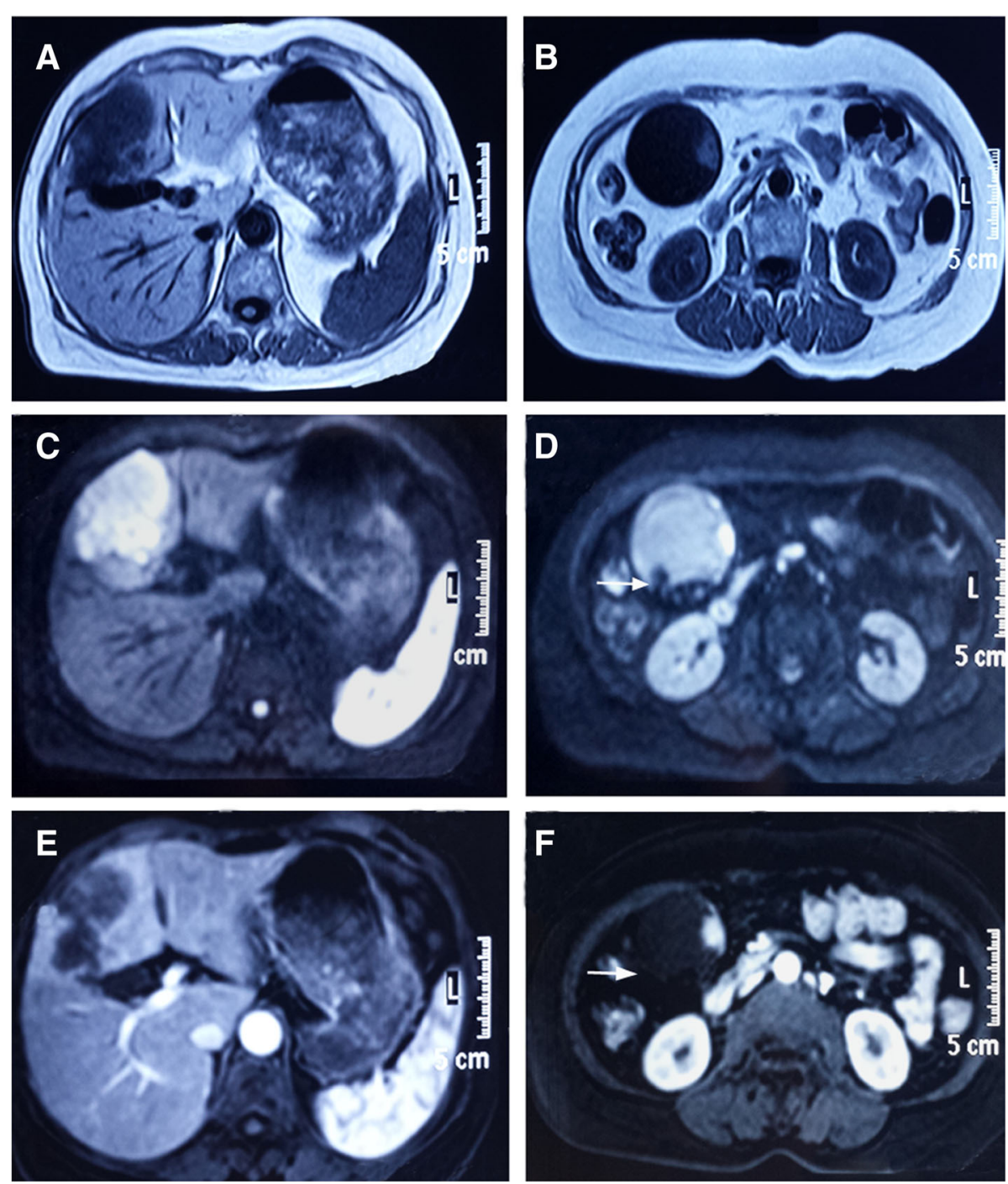

Fig. 2 Abdominal magnetic resonance imaging-scan demonstrating gallbladder stones and $3 \times 3 \mathrm{~cm}$ mass in gallbladder, and $6.2 \times 4.5 \mathrm{~cm}$ lesion segment IVb of the liver. $\mathbf{a}$ and $\mathbf{b}$ T1-weighted images, $\mathbf{c}$ and $\mathbf{d}$ T2-weighted images, $\mathbf{e}$ and $\mathbf{f}$ Artery phase, $\mathbf{d}$ and $\mathbf{f}$, arrow: Gallbladder stones
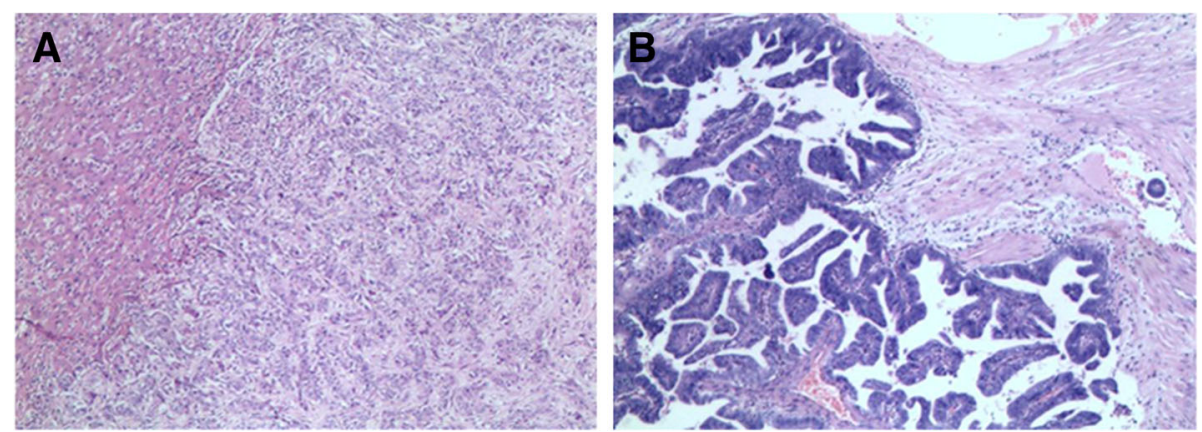

Fig. 3 Histopathological examination of resected specimen (Hematoxylin-eosin staining, magnification× 100). a Combined hepatocellular cholangiocarcinoma in segment IVb of liver, $\mathbf{b}$ Well-differentiated papillary adenocarcinoma invading the muscularis propria 
double SPC. A high incidence of synchronous primary cancers has been found in liver. Lee $\mathrm{JH}$ et al. reported that the most common synchronous sites were colorectal cancer (37.2\%), followed by lung cancer (18.6\%), esophageal cancer (16.8\%), liver cancer (9.7\%), kidney cancer (4.4\%) and gastric cancer (3.4\%) [4]. A study by Zeng QA et al. showed that the incidence of synchronous cancer in liver cancer patients was 3.4\% [1]. SPC rarely occurs in the gallbladder (14 cases total). SPC in both of the above organs is rarely reported. Due to the lack of apparent radiological features, this kind of SPC is not easily differentiated from hepatic metastasis of gallbladder carcinoma. There are 7 cases reported in the English language so far [5-11]. The results can be seen in Table 1.

In this series of 7 cases reviewed in literature, only one case was correctly diagnosed before operation (GC and intrahepatic bile duct carcinoma). One case was diagnosed as GC and hepatocellular carcinoma by intraoperative frozen section. The detailed diagnostic procedure is shown in Fig. 4. CT and MRI are considered the best diagnostic techniques for cancer staging and surgical strategy guiding. Although the patient accepted the CT and MRI examinations, we did not take SPC of GC and $\mathrm{CHC}$ as a possible diagnosis before operation. The reasons may be: 1) low incidence and lack of experience; 2 ) lack of obvious symptoms and typical radiological features: both metastatic lesions of $\mathrm{GC}$ and $\mathrm{CHC}$ manifested hypovascular lesions in the liver; 3 ) non-specific tumor markers. Most of patients with $\mathrm{CHC}$ had elevated serum level of AFP [12]. The case presented here had normal level of AFP and elevated serum levels of CEA, CA125 and CA19-9. These elevated tumor markers were commonly detected in patients with GC. We searched literatures [13-16] and listed the main differences between SPC and GC with hepatic metastasis in
Table 2. Recently, the studies showed that positron emission computed tomography (PET) scan was useful in differentiating malignant from benign disease, in preoperative staging, and detecting postoperative residual disease [13-17]. Histopathology from biopsy or liver resection remains the golden diagnostic standard [1]. If the lesions can be surgically resected, histological examination of the whole lesion is more reliable than a biopsy, because insufficient, missed or ample necrotic tissue may not be representative of the entire lesion [18]. Needle-tract implantation and complications (such as prolonged internal bleeding, bile leakage and infection) are other reasons that preoperative biopsy of the liver is not recommended [19].

Curative resection, if possible, most effectively prolongs patient survival. However, in cases with SPC in the liver and gallbladder, the choice of treatment strategy should be made carefully in conjunction with the treatment for the second malignancy. There are few reports on how to treat patients with this rare disease, which remains a key challenge. The patient presented here underwent laparotomy, which included cholecystectomy, resection of liver segment $\mathrm{V}$, of the lower part of segment IV and partial segment VIII, regional lymphadenectomy and resection of lesions on diaphragm. Unfortunately, the patient died of widespread metastasis 8 months after the operation. Reviewing the literature, the longest survival of 17 months happened in the patient with PC and hepatocellular carcinoma.

The pathogenesis of SPC has not been clarified, some factors such as genetic factors, hormones, environmental carcinogens, dietary factors, infective agents, previous therapy, alcohol and smoking are involved [20, 21]. Gallbladder stones and/or infectious agents develop cancer as a result of recurrent trauma and chronic inflammation [8]. One reasonable hypothesis focuses on chronic

Table 1 Literature Review of Synchronous Primary Cancers Occurring in Gallbladder and Liver

\begin{tabular}{|c|c|c|c|c|c|c|c|c|}
\hline Cases & Species & $\begin{array}{l}\text { Age }(y) / \\
\text { Sex }\end{array}$ & $\begin{array}{l}\text { Risk of liver } \\
\text { tumor }\end{array}$ & $\begin{array}{l}\text { Gallbladder } \\
\text { stones }\end{array}$ & $\begin{array}{l}\text { Location of tumor } \\
\text { in liver }\end{array}$ & $\begin{array}{l}\text { Histopathological } \\
\text { examination }\end{array}$ & Treatment & $\begin{array}{l}\text { Prognosis } \\
\text { (Months) }\end{array}$ \\
\hline $\begin{array}{l}\text { Imada J et al } \\
\text { [5] }\end{array}$ & Human & $70 / F$ & HCV/Cirrhosis & No & SVII & $\mathrm{HCC} / \mathrm{CCD} / \mathrm{GC}^{\mathrm{w}}$ & Conservative treatment & $\begin{array}{l}\text { 4/Die of Liver } \\
\text { failure }\end{array}$ \\
\hline $\begin{array}{l}\text { Taniai } \mathrm{N} \text { et al } \\
{[6]}\end{array}$ & Human & $83 / F$ & N/A & With & SVIII & $\mathrm{ICC}^{\mathrm{w}} / \mathrm{GC}$ & Laparotomy & N/A \\
\hline $\begin{array}{l}\text { La Greca G et } \\
\text { al [7] }\end{array}$ & Human & N/A & N/A & With & SIV & $\mathrm{HCC}^{\mathrm{W}} / \mathrm{GC}$ & Laparotomy & N/A \\
\hline Kin JW et al [8] & Human & $63 / M$ & HBV/Cirrhosis & With & SIII & $\mathrm{HCC} / \mathrm{GC}^{\mathrm{m}}$ & Laparotomy & 17/Alive \\
\hline $\begin{array}{l}\text { Unver M et al } \\
\text { [9] }\end{array}$ & Human & $65 / M$ & $\begin{array}{l}\text { HBV/without } \\
\text { cirrhosis }\end{array}$ & With & SIVNII & $\mathrm{HCC} / \mathrm{GC}^{\mathrm{w}}$ & Laparotomy & 6/Alive \\
\hline Lu J et al [10] & Human & $67 / F$ & No & No & SIVN & $\mathrm{HNC/GC}$ & Laparotomy & N/A \\
\hline $\begin{array}{l}\text { Jakab C et al } \\
{[11]}\end{array}$ & $\begin{array}{l}\text { Pogona } \\
\text { vitticeps }\end{array}$ & N/A & N/A & No & Peripheral part & $\mathrm{ICC}^{\mathrm{W}} / \mathrm{GC}^{\mathrm{w}} / \mathrm{GA}$ & Laparotomy & Euthanasia \\
\hline
\end{tabular}

$M$ male, $F$ female, $S$ segment, HCC hepatocellular carcinoma, GC gallbladder adenocarcinoma, CCD adenocarcinoma of the common bile duct, HNC hepatic neuroendocrine carcinoma, $w$ well differentiated, $m$ moderately differentiated, ICC intrahepatic cholangiocellular carcinoma, GA gallbladder adenoma 


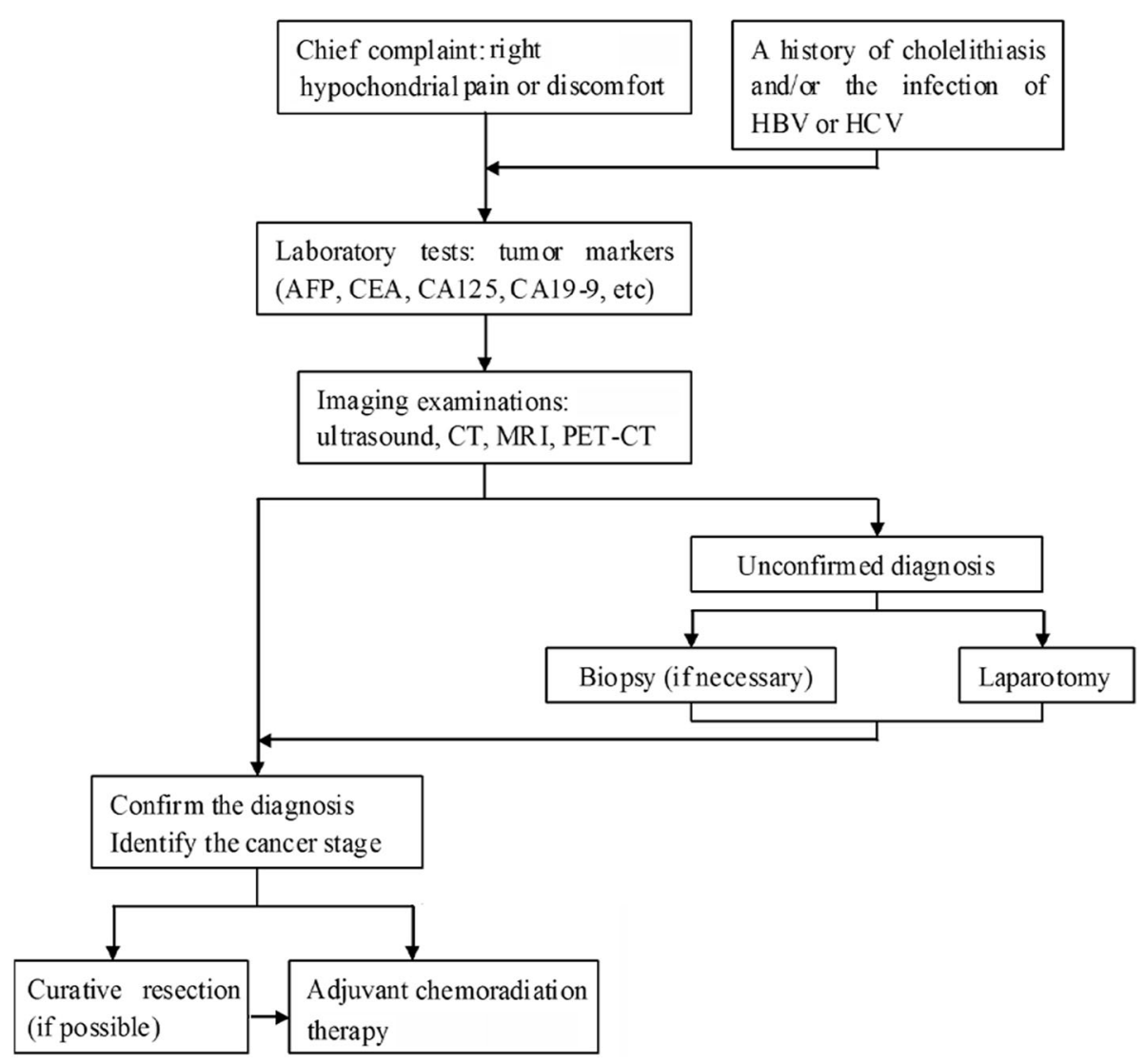

Fig. 4 Clinical algorithms for the evaluation of synchronous primary cancers in liver and gallbladder. AFP = alpha-fetoprotein, CEA = carcinoembryonic antigen, CA125 = carbohydrate antigen125, CT = computed tomography, MRI = magnetic resonance imaging, PET-CT = positron emission computerized tomography

Table 2 Differential Diagnosis Between SPC and GC with HM

\begin{tabular}{lll}
\hline & SPC & GC with HM \\
\hline Incidences & Rare, 8 cases & Geography/ethnicity $\left(1.1 \sim 27 / 10^{5}\right)$ \\
Agender $(y r s)$ & Major in F $(F / M=2 / 1)$ & Major in $F(F / M=2 \sim 6 / 1)$ \\
HBV/HCV & Old age $($ Mean $=68.8)$ & Old age $($ Mean $=67)$ \\
Gallbladder stones & Partial patients & Not \\
AFP & $50 \%$ & $\sim 85 \%$ \\
CEA & Elevated in partial patients & Not \\
CA19-9 & Elevated & Elevated \\
Number of liver masses & Elevated & Elevated \\
Location of liver masses & Simple or multiple & Multiple \\
Invasion of GC & Any segments in the liver & Adjacent to the gallbladder \\
Imaging manifestation & Not found & Presentation \\
\hline
\end{tabular}

SPC synchronous primary cancers, GC gallbladder adenocarcinoma, $H M$ hepatic metastasis, $M$ male, $F$ female, $H B V$ hepatitis $B$ virus, $H C V$ hepatitis $C$ virus, $A F P$ alpha-fetoprotein, CEA carcinoembryonic antigen, CA19-9 carbohydrate antigen 19-9 
irritation of the mucosa (e.g., from the physical presence of the stones and/or superimposed chronic infection such as from Salmonella typhi) leading to dysplasia (perhaps abetted by mutagenic secondary bile acids) and terminating in malignant change [22]. $\mathrm{CHC}$ is a rare tumor, accounting for $1.3 \%$ of primary hepatic malignancies [23]. Studies show that many etiologies, including the infection of hepatitis $\mathrm{B}$ and $\mathrm{C}$ virus, allelic losses, and divergent differentiation of hepatic stem/progenitor cells were associated with $\mathrm{CHC}$ [24-26]. Our previous study also suggested that $\mathrm{CHC}$ might arise from hepatic progenitor cells [27]. Otherwise, many studies manifest that chronic inflammation has been suggested as an important step to hepatocarcinogenesis $[28,29]$. In this case, we speculate that chronic infection of gallbladder affects surrounding liver tissues, leading to inflammation of surrounding liver tissues, which was demonstrated by enhancement of segment IV during arterial phase (Fig. 2e). Liver inflammation promotes aberrant self-renewal and irritates malignant transformation of hepatic progenitor cells. Because of the rarity of SPC in the gallbladder and liver, clinical data is limited. So the detailed etiology and mechanism still need further clarification.

In conclusion, synchronous primary cancers involving both the liver and gallbladder are regarded as a rare occurrence. Due to the lack of apparent radiological features, it is not easily differentiated from hepatic metastasis of GC. It is necessary to develop more accurate diagnostic techniques and administer more refined treatment strategies to correctly diagnose SPC.

\begin{abstract}
Abbreviations
AFP: alpha-fetoprotein; CA125: carbohydrate antigen125; CEA: carcinoembryonic antigen; CHC: combined hepatocellular cholangiocarcinoma; CT: computed tomography; GC: Gallbladder carcinoma; MRI: magnetic resonance imaging; PET: positron emission computed tomography; SPC: synchronous primary cancers
\end{abstract}

\section{Acknowledgements}

No applicable.

\section{Funding}

This work is supported by The State Key Project on Inflection Disease of China (Grant No. 2012ZX10002016-004 and 2012ZX10002010-001-004).

\section{Availability of data and materials}

All the data supporting our findings is contained within the manuscript. The raw data will not be made available in order to protect the participants' identity.

\section{Authors' contributions}

ZZG, CY and ZL designed the idea and wrote the manuscript. JR, ZYJ and WJ participated in designing the study and recruitment of the data, and drafted the manuscript. CXP and RL participated in the design of the study and did the language check. All authors read and approved the manuscript.

\section{Ethics approval and consent to participate}

The study was approved by Institutional Review Board of Tongj Hospital, Tongji Medical College, Huazhong University of Science and Technology. The patient and her relations have signed an informed consent form before inclusion.
Consent for publication

Documented written consent from the patient was obtained to report the details of the case.

\section{Competing interests}

The authors declare that they have no competing interests for this research.

\section{Publisher's Note}

Springer Nature remains neutral with regard to jurisdictional claims in published maps and institutional affiliations.

\section{Author details}

${ }^{1}$ Hepatic Surgery Center, Institute of Hepato-Pancreato-Bililary Surgery, Tongji Hospital, Tongji Medical College, Huazhong University of Science and Technology, Wuhan 430030, People's Republic of China. ${ }^{2}$ Department of Pediatrics, Union Hospital, Tongji Medical College, Huazhong University of Science and Technology, Wuhan 430022, Hubei Province, People's Republic of China. ${ }^{3}$ Hepatic Surgery Center, Tongji Hospital, Tongji Medical College, Huazhong University of Science and Technology, 1095 Jiefang Avenue, Wuhan 430030, People's Republic of China. ${ }^{4}$ Department of Pediatrics, Pennsylvania State University College of Medicine, Hershey, PA 17033, USA. ${ }^{5}$ Hepatic Surgery Center, Department of Surgery, Tongji Hospital, Tongji Medical College, Huazhong University of Science and Technology, Wuhan 430030, People's Republic of China.

Received: 10 May 2018 Accepted: 17 October 2018

Published online: 29 October 2018

\section{References}

1. Zeng QA, Qiu J, Zou R, et al. Clinical features and outcome of multiple primary malignancies involving hepatocellular carcinoma: a long-term follow-up study. BMC Cancer. 2012;12:148.

2. Demandante CG, Troyer DA, Miles TP. Multiple primary malignant neoplasms: case report and a comprehensive review of the literature. Am J Clin Oncol. 2003;26:79-83.

3. Warren S, Gates O. Multiple primary maligant tumors: a survey of the literature and a statistical study. Am J Cancer. 1932;16:1358-414.

4. Lee JH, Bae JS, Ryu KW, Lee JS, Park SR, Kim CG, Kook MC, Choi IJ, Kim YW, Park JG, Bae JM. Gastric cancer patients at high-risk of having synchronous cancer. World J Gastroenterol. 2006:12:2588-92.

5. Imada J, Hoshino H, Nishimura D, et al. Case report: multiple cancers: hepatocellular carcinoma and adenocarcinomas of the common bile duct and the gall-bladder in a woman with primary biliary cirrhosis. J Gastroenterol Hepatol. 1996;11:546-50.

6. Taniai N, Onda M, Tajiri T, et al. Synchronous carcinoma of the gallbladder in a patient with intrahepatic bile duct carcinoma. Hepatogastroenterology. 2000:47:121-4.

7. La Greca G, Barbagallo F, Rodolico M, et al. Hepatocarcinoma, gallstone disease and gallbladder carcinoma: a case report of a rare incidental association. Chir Ital. 2004;56:571-4

8. Kim JW, Han JW, Jung SY, et al. Synchronous double primary malignant tumor of the gallbladder and liver: a case report. World J Surg Oncol. 2011;9:84.

9. Unver M, Ozturk S, Bozbiyik $O$, et al. Incidental early gallbladder carcinoma with hepatocellular carcinoma: a rare synchronous double primary malignant tumor. J Med Cases. 2014;5:561-3.

10. Lu J, Xiong XZ, Cheng NS. Hepatobiliary and pancreatic: coexisting cancers: hepatic neuroendocrine carcinomas with gallbladder adenocarcinoma. J Gastroenterol Hepatol. 2014;29:1343.

11. Jakab C, Rusvai M, Szabó Z, et al. Claudin-7-positive synchronous spontaneous intrahepatic cholangiocarcinoma, adenocarcinoma and adenomasof the gallbladder in a bearded dragon (Pogona vittticeps). Acta Vet Hung. 2011;59:99-112

12. Kim KH, Lee SG, Park EH, et al. Surgical treatments and prognoses of patients with combined hepatocellular carcinoma and cholangiocarcinoma. Ann Surg Oncol. 2009;16:623-9.

13. Groot Koerkamp B, Fong Y. Outcomes in biliary malignancy. J Surg Oncol. 2014;110:585-91.

14. Rakić M, Patrlj L, Kopljar M, et al. Gallbladder cancer. Hepatobiliary Surg Nutr 2014;3:221-6. 
15. Hundal R, Shaffer EA. Gallbladder cancer: epidemiology and outcome. Clin Epidemiol. 2014;6:99-109.

16. Dwivedi AN, Jain S, Dixit R. Gall bladder carcinoma: aggressive malignancy with protean loco-regional and distant spread. World J Clin Cases. 2015;3: 231-44.

17. Dutta U. Gallbladder cancer: can newer insights improve the outcome? J Gastroenterol Hepatol. 2012;27:642-53.

18. Bret PM, Labadie M, Bretagnolle M, et al. Hepatocellular carcinoma: diagnosis by percutaneous fine needle biopsy. Gastrointest Radiol. 1988;13: 253-5.

19. Kim SH, Lim HK, Lee WJ, et al. Needle-tract implantation in hepatocellular carcinoma: frequency and $C T$ findings after biopsy with a 19.5-gauge automated biopsy gun. Abdom Imaging. 2000;25:246-50.

20. Kim C, Chon H, Kang B, Jung JP, Kim JW. Prediction of metachronous multiple primary cancers following the curative resection of gastric cancer. BMC Cancer. 2013;13:394

21. Park SL, Caberto CP, Lin Y, et al. Association of cancer susceptibility variants with risk of multiple primary cancers: the population architecture using genomics and epidemiology study. Cancer Epidemiol Biomark Prev. 2014;23: 2568-78.

22. Stinton LM, Eldon A, Shaffer EA. Epidemiology of gallbladder disease: Cholelithiasis and Cancer. Gut Liver. 2012;6:172-87.

23. Wachtel MS, Zhang $Y, X u T$, et al. Combined hepatocellular cholangiocarcinomas; analysis of a large database. Clin Med Pathol. 2008;1:43-7.

24. O'Connor K, Walsh JC, Schaeffer DF. Combined hepatocellularcholangiocarcinoma (cHCC-CC): a distinct entity. Ann Hematol. 2014;13:317-22.

25. Komuta M, Spee B, Vander Borght S, et al. Clinicopathological study on cholangiolocellular carcinoma suggesting hepatic progenitor cell origin. Hepatology. 2008;47:1544-56.

26. Fujii $\mathrm{H}$, Zhu XG, Matsumoto T, et al. Genetic classification of combined hepatocellular-cholangiocarcinoma. Hum Pathol. 2000;31:1011-7.

27. Zhang F, Chen XP, Zhang W, et al. Combined hepatocellular cholangiocarcinoma originating from hepatic progenitor cells: immunohistochemical and double-fluorescence immunostaining evidence. Histopathology. 2008;52:224-32.

28. Berasain C, Castillo J, Perugorria MJ, et al. Inflammation and liver cancer: new molecular links. Ann N Y Acad Sci. 2009;1155:206-21.

29. Mantovani A, Allavena P, Sica A, et al. Cancer-related inflammation. Nature. 2008:454:436-44.

\section{Ready to submit your research? Choose BMC and benefit from:}

- fast, convenient online submission

- thorough peer review by experienced researchers in your field

- rapid publication on acceptance

- support for research data, including large and complex data types

- gold Open Access which fosters wider collaboration and increased citations

- maximum visibility for your research: over $100 \mathrm{M}$ website views per year

At BMC, research is always in progress.

Learn more biomedcentral.com/submissions 